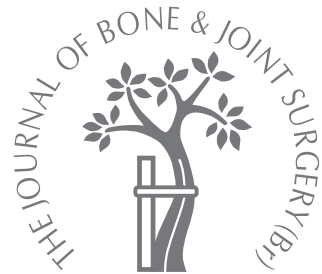

I.-Y. Ok, S.-J. Kim

From The Catholic University of Korea, Seoul, Korea
I.-Y. Ok, MD, PhD, Professor Department of Orthopaedic

Surgery

KangNam St. Mary's Hospital, The Catholic University of Korea School of Medicine, 505 Banpo-dong, Seocho-gu, Seoul, 137-040, Republic of Korea.

S.-J. Kim, MD, PhD, Assistant Professor

Department of Orthopaedic

Surgery

Uijongbu St. Mary's Hospital The Catholic University of Korea School of Medicine, 65-1 Kumho-dong, Uijongbu-si, Kyunggi-do, 480-717, Republic of Korea.

Correspondence should be sent to Dr S.-J. Kim; e-mail:

peter@catholic.ac.

(C)2007 British Editorial Society of Bone and Joint Surgery doi:10.1302/0301-620X.89B3. $18559 \$ 2.00$

$J$ Bone Joint Surg $[\mathrm{Br}]$ 2007;89-B:396-7.

Received 21 August 2006;

Accepted 19 October 2006

- CASE REPORT

\title{
Remodelling of the distal radius after epiphysiolysis and lengthening
}

\begin{abstract}
Arrest of growth of the distal radius is rare but will produce deformity of the wrist. We corrected angular deformity and shortening of the distal radius by epiphysiolysis and gradual lengthening without a corrective osteotomy.
\end{abstract}

Little is known about remodelling of the distal radius in children, but the spontaneous correction of angular deformities of growing long bones is a well-known phenomenon in clinical practice. ${ }^{1-3}$ Because growth arrest of the distal radius is rare, treatment options are limited. Here we describe a case treated for growth arrest of the distal radial physis.

\section{Case report}

A nine-year-old girl was seen with a deformity of the right wrist. Plain radiographs (Fig. 1), and an MRI (Fig. 2) showed physeal bar formation at the distal radius and a complex deformity. She had injured her right wrist three years previously and had been treated conservatively. Joint movement was normal except for ulnar and radial deviation. The physeal bar was resected and bone cement (polymethylmethacrylate) interposed in the distal radial physis. Corticotomy was performed and an Ilizarov external fixator (U \& I Co-operation, Gyeonggi-do, Korea) applied to the distal

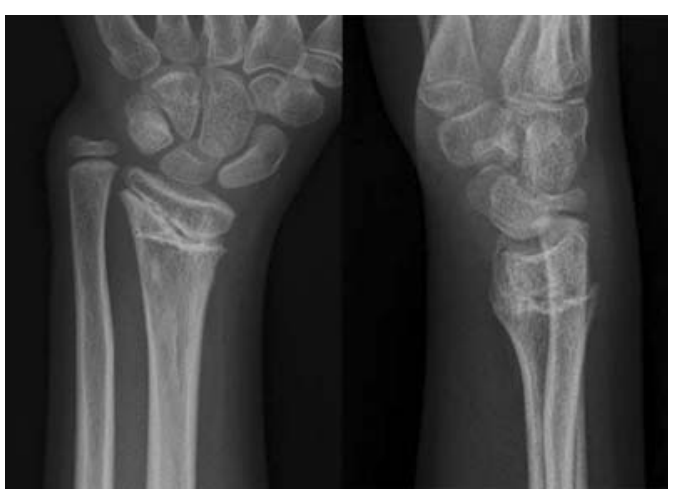

Fig. 1

Radiographs of the right wrist showing loss of radial inclination and height, with fusion of the radial side of the growth plate at the distal radius radius. Seven days later, lengthening of the radius was started at $1 \mathrm{~mm} / \mathrm{day}$ and was terminated after $2 \mathrm{~cm}$ of gain when the distal radial physis and ulnar joint line were level (Fig. 3). Two years later the radial inclination and height had corrected spontaneously, and the deformity was cured (Fig. 4).

\section{Discussion}

Growth arrest of the distal radius is rare and is related to many factors, including the severity of trauma, the degree of displacement, and repeated or delayed reduction. ${ }^{4}$ Clinically, relative lengthening of the ulna accentuates degeneration of the triangular fibrocartilage complex, ${ }^{5}$ and radial shortening can disrupt the mechanics of the distal radioulnar joint and result in loss of movement. ${ }^{6}$

The treatment of growth arrest of the distal radius aims to re-establish normal growth and correct deformity. Residual deformities can be corrected by equalising the lengths of the

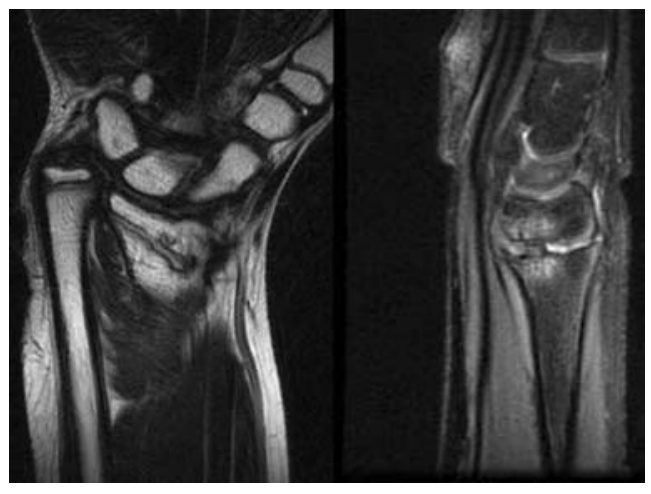

Fig. 2

Physeal bar formation on the voloradial aspect of the distal radius seen on MRI. 


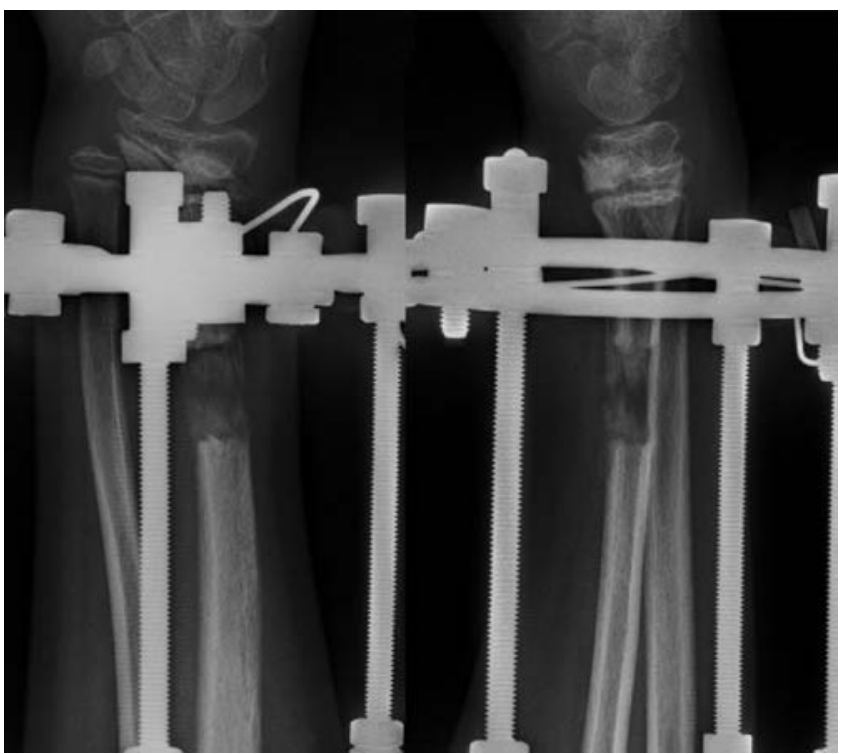

Fig. 3

Radiographs of the right wrist taken one month after the initial operation.

radius and ulna by resection of the radial physeal bridge and epiphysiodesis of the distal ulna, or by ulnar shortening. ${ }^{7}$ However, an angular deformity of the distal radius of more than $20^{\circ}$ will probably not correct with growth after excision of the physeal bar, and usually requires an osteotomy. ${ }^{8}$

In this case, corrective osteotomy was not performed. The physeal bar was resected with interposition of bone cement and bone lengthening. Osteotomy and lengthening can increase the blood flow to adjacent tissues and stimulate the growth plate of the distal radius. The distal growth plate accounts for $75 \%$ of the length of the bone, ${ }^{9}$ permitting substantial remodelling.

No benefits in any form have been received or will be received from a commercial party related directly or indirectly to the subject of this article.

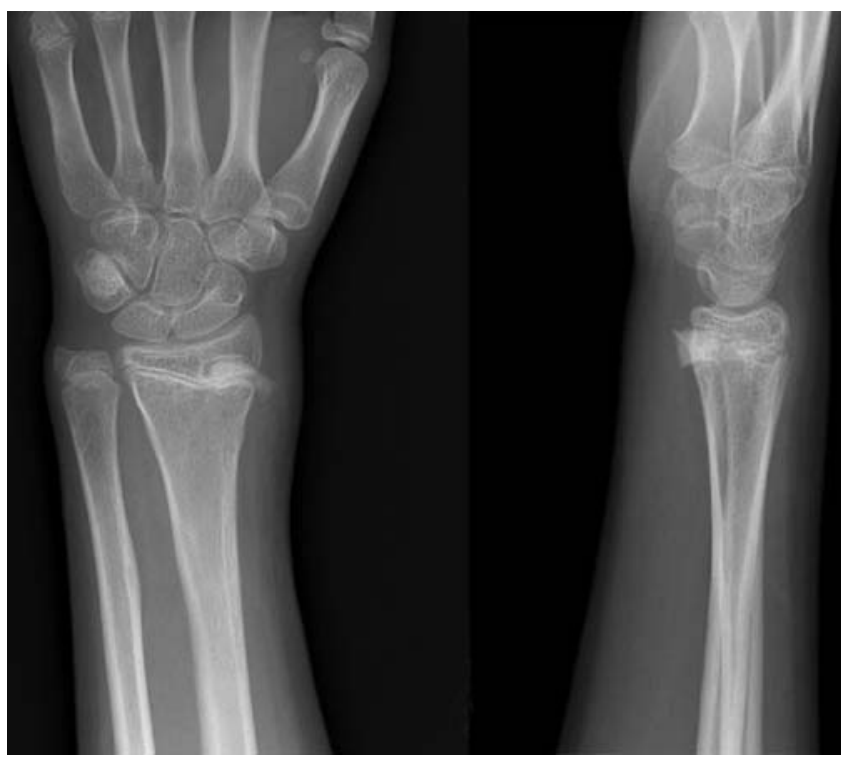

Fig. 4

Radiographs of the right wrist taken two years after the initial operation.

\section{References}

1. Friberg $\mathbf{S}$. Remodeling after distal forearm fractures in children: I. the effect of residual angulation on the spatial orientation of the epiphysealplates. Acta Orthop Scand 1979;50:537-46.

2. Friberg $\mathbf{S}$. Remodeling after distal forearm fractures in children: II.: the final orientation of the proximal and distal epiphyseal plates of the radius. Acta Orthop Scand 1979;50:731-9.

3. Friberg S. Remodeling after distal forearm fractures in children: III. correction of residual angulation in fracture of the radius. Acta Orthop Scand 1979;50:741-9.

4. Davis DR, Green DP. Forearm fractures in children: pitfalls and complications. Clin Orthop 1976;120:172-83.

5. Palmer AK, Glisson RR, Werner FW. Relationship between ulnar variance and triangular fibrocartilage complex thickness. J Hand Surg 1984;9:681-2.

6. Adams BD. Effects of radial deformity on distal radioulnar joint mechanics. J Hand Surg 1993;18:492-8.

7. Crawford AH. Pitfalls and complications of fractures of the distal radius and ulna in childhood. Hand Clin 1988;4:403-13.

8. Peterson HA. Partial growth plate arrest and its treatment. J Pediatr Orthop 1984;4:24658.

9. Salter RB, Harris WR. Injuries involving the epiphyseal plate. J Bone Joint Surg [Am] 1963;45-A:587-622. 